\title{
ASTROMETRIC AND GEODETIC GOALS FOR THE CHINESE VLBI NETWORK PROJECT
}

\author{
YE SHUHUA AND QIAN ZHIHAN \\ Shanghai Observatory, Chinese Academy of Sciences \\ 80 Nandan Road \\ Shanghai 200030, People's Republic of China
}

ABSTRACT. This paper briefly introduces the current status of the Chinese VLBI Network (CVN) Project and its astrometric and geodetic goals.

\section{Current Status of CVN Project}

At present, the CVN project consists of three dedicated VLBI stations, two part-time VLBI stations, and a data analysis center. More information about the progress of the CVN project is as follows:

1.1 VLBI Stations

(1) Sites

\begin{tabular}{clccc}
\hline Code & \multicolumn{1}{c}{ Station } & $\begin{array}{c}\text { Antenna } \\
(\mathrm{m})\end{array}$ & $\begin{array}{c}\text { Lat. N } \\
\left({ }^{\circ},\right)^{\prime}\end{array}$ & $\begin{array}{c}\text { Long. E } \\
\left.\left({ }^{\circ},\right)^{\prime}\right)\end{array}$ \\
\hline SH & Sheshan Radio Astronomy Station & 25 & 3106 & 12112 \\
UR & Urumqi Radio Astronomy Station & 25 & 4330 & 8713 \\
KM & Kunming Radio Astronomy Station & 32 & 2501 & 10247 \\
MY & $\begin{array}{c}\text { Miyun M-wave Synthesis } \\
\text { Radio Astronomy Station }\end{array}$ & $\begin{array}{c}47 \\
\text { (equiv.) }\end{array}$ & 4040 & 11758 \\
QH & $\begin{array}{c}\text { Qinghai Mm-wave Radio } \\
\text { Astronomy Station }\end{array}$ & 13.7 & 3721 & 9736 \\
& $\quad$ & & & \\
\hline
\end{tabular}


(2) Equipment

\begin{tabular}{|c|c|c|c|c|c|c|}
\hline \multirow{2}{*}{ Items } & \multirow{2}{*}{ Station } & \multicolumn{3}{|c|}{ Dedicated } & \multicolumn{2}{|c|}{ _Part-Time } \\
\hline & & $\overline{\mathrm{SH}}$ & UR & $\mathrm{KM}$ & $\mathrm{MY}$ & $\mathrm{QH}$ \\
\hline \multicolumn{2}{|l|}{ Antenna } & $\dagger$ & + & - & $t$ & $\dagger$ \\
\hline \multirow[t]{10}{*}{ Receivers } & $330-\mathrm{MHz}$ & $t$ & + & - & + & \\
\hline & $610-\mathrm{MHz}$ & + & + & - & & \\
\hline & $1.4-\mathrm{GHz}$ & $t$ & + & - & & \\
\hline & $1.6-\mathrm{GHz}$ & $\dagger$ & + & - & & \\
\hline & 2.3-GHz & $\dagger$ & + & - & & \\
\hline & $4.9-\mathrm{GHz}$ & $t$ & + & - & & \\
\hline & 8.4-GHz & $t$ & + & - & & \\
\hline & $10.7-\mathrm{GHz}$ & $t$ & + & - & & \\
\hline & $12.2-\mathrm{GHz}$ & $\dagger$ & + & - & & \\
\hline & 22.2-GHz & - & - & - & & $\dagger$ \\
\hline \multirow{2}{*}{ Data Acquisition Terminals } & Mk II & t & $t$ & $t$ & + & + \\
\hline & $\begin{array}{l}\text { Mk III } \\
\text { or VLBA }\end{array}$ & $\dagger$ & - & - & & - \\
\hline \multirow[t]{2}{*}{ Frequency Standards } & $\mathrm{H}$ maser & $\dagger$ & + & + & & - \\
\hline & $\mathrm{Rb}$ & $\dagger$ & $\dagger$ & $\dagger$ & - & \\
\hline \multirow[t]{2}{*}{ Timing Receivers } & Loran-C & $\dagger$ & $\dagger$ & $\dagger$ & & \\
\hline & GPS & $\dagger$ & + & - & - & - \\
\hline \multicolumn{2}{|l|}{ Operation Start } & 87 & 92 & 94 & 92 & 92 \\
\hline
\end{tabular}

Codes: † Available; + Fabrication started or ordered; - Planned.

\subsection{VLBI Data Analysis Center}

The data analysis center of CVN is located at Shanghai and operated by Shanghai Observatory, Chinese Academy of Sciences. The main facilities in the VLBI data analysis center are as follows: 


\begin{tabular}{|c|c|c|}
\hline Facilities & Available & Remark \\
\hline \multirow{2}{*}{$\begin{array}{r}\text { VLBI Correlator: } \mathrm{S}-\mathbf{2} \\
\qquad \mathrm{S}-3\end{array}$} & 1988 & Compatible with Mk II \\
\hline & $1993 / 94$ & Compatible with Mk III and VLBA \\
\hline \multirow[t]{2}{*}{ Computer: HP-1000 F series } & 1985 & $\begin{array}{l}\text { For the data analysis of } \\
\text { astrometric and geodetic VLBI } \\
\text { Mk III experiments. }\end{array}$ \\
\hline & 1988 & $\begin{array}{l}\text { For the postprocessing of the data } \\
\text { from } \mathrm{S}-2 \text { correlator and the data } \\
\text { analysis of continuum and line } \\
\text { VLBI experiments. }\end{array}$ \\
\hline VAX 3800 & 1991 & VLBI data analysis \\
\hline Sun $4 / 11$ & 1991 & VLBI data analysis \\
\hline
\end{tabular}

\section{Astrometric and Geodetic Goals for the CVN Project}

- To measure the positions of the extragalactic compact radio sources (one source $/ 5^{\circ} \times 5^{\circ}$; declination: $-30^{\circ}$ to $+90^{\circ}$ ) for the establishment of the radio reference system;

- To monitor the structure variations and the proper motions of the radio sources for the maintenance of the radio reference system;

- To measure the positions and proper motions of radio stars and cosmic masers associated with late-type stellars for the linkage between the radio and optical reference systems;

- To measure the positions and proper motions of the pulsars combining the pulsar-timing data for the determination of the equinox;

- To measure the Earth rotation parameters;

- To measure the positions of the CVN stations with $\mathrm{mm}$ accuracy combining the Chinese SLR and GPS networks for the establishment of the Chinese Crustal Deformation Monitoring Network (CCDMN) and the global terrestrial reference system;

- To measure the crustal motions between the eastern, north-western, and south-western regions of China;

- To measure the relative motions between the Chinese continent and the surrounding plates, e.g., Pacific, North American, Australian, Indian, and Philippine plates and to monitor the stability of the Eurasian plate;

- To control the orientation and scale of the Chinese National Geodetic Control Network. 